\title{
Effects of bushing profiles on the elastohydrodynamic lubrication performance of the journal bearing under steady operating conditions
}

\author{
Chongpei Liu, Bin Zhao, Wanyou Li, and Xiqun $\mathrm{Lu}^{*}$ \\ College of Power and Energy Engineering, Harbin Engineering University, Harbin, PR China
}

Received: 4 December 2018 / Accepted: 12 February 2019

\begin{abstract}
The bushing profiles have important effects on the performance of journal bearing. In this article, the effects of plain profile, double conical profile, and double parabolic profile on the elastohydrodynamic lubrication of the journal bearing under steady operating conditions are investigated. The journal misalignment and asperity contact between journal and bushing surface are considered, while the modification of the bushing profiles due to running-in is neglected. Finite element method is used for the elastic deformation of bushing surface, while the numerical solution is established by using finite difference method and overrelaxation iterative method. The numerical results reveal that the double parabolic profile with appropriate size can significantly increase the minimum film thickness and reduce the asperity contact pressure and friction, while the maximum film pressure, load-carrying capacity, and leakage flow rate change slightly under steady operating conditions. This study may help to reduce the edge wear and prolong the service life of the journal bearing.
\end{abstract}

Keywords: Journal bearing / bushing profiles / misalignment / asperity contact / wear

\section{Introduction}

Journal bearing is one of the most critical friction pairs in diesel engine, whose lubrication performance directly affects the reliability and durability of the engine. Since the elastic deformations, journal misalignment, and machining errors are unavoidable in actual operation, it is found that the bushing shows severe edge wear, as shown in Figure 1, which deteriorates the lubrication condition and shortens the service life of the bearing. In such cases, the edge wear needs to be investigated and effective ways should be presented to reduce it.

Some important works [1-3] have laid a foundation for the tribological analysis. In these works, the effects of rough surface were studied, and the calculation formulas of asperity contact pressure between rough surfaces were proposed. Dufrane et al. [4] analyzed the effect of geometric changes due to wear on the lubrication performance of journal bearings, which revealed that a limited amount of wear may enhance the performance. Fillon and Bouyer [5] studied the thermohydrodynamic performance of a worn plain journal bearing under a static load. The results showed that the worn journal bearing can present not only disadvantages but also advantages, such as better dynamic

\footnotetext{
* e-mail: luxiqun@hrbeu.edu.cn
}

stability and lower temperature. Bouyer et al. [6] completed an experimental study to complement the previous work [5]. The study showed that when considering the real wear defect, the theoretical results can agree well with the experimental data. Chun and Khonsari [7] presented a wear study of the journal bearing for a single-cylinder engine during start-up and coast-down. The study showed that after one turn on and off of an ignition switch, the accumulated wear volume will increase with the increasing surface roughness. Based on computational fluid dynamics (CFD) and fluid-structure interaction (FSI) method, Wang et al. [8] investigated the performance of worn water-lubricated plain journal bearings with the effects of elastic deformation and cavitation, and the results of the CFD and FSI method were verified by the experimental ones. The results showed that, for the worn water-lubricated plain journal bearings under the same Sommerfeld number, the maximum film pressure and maximum bearing deformation increase with the increasing of wear depth, and by contrast, the friction coefficient decreases with the increasing of wear depth. Kalavathi et al. [9] studied the influence of surface roughness on porous journal bearings with heterogeneous slip/no-slip surface. The results revealed that the load-carrying capacity and pressure distribution will increase with increasing surface roughness, and these two characteristics will decrease with increasing permeability. 


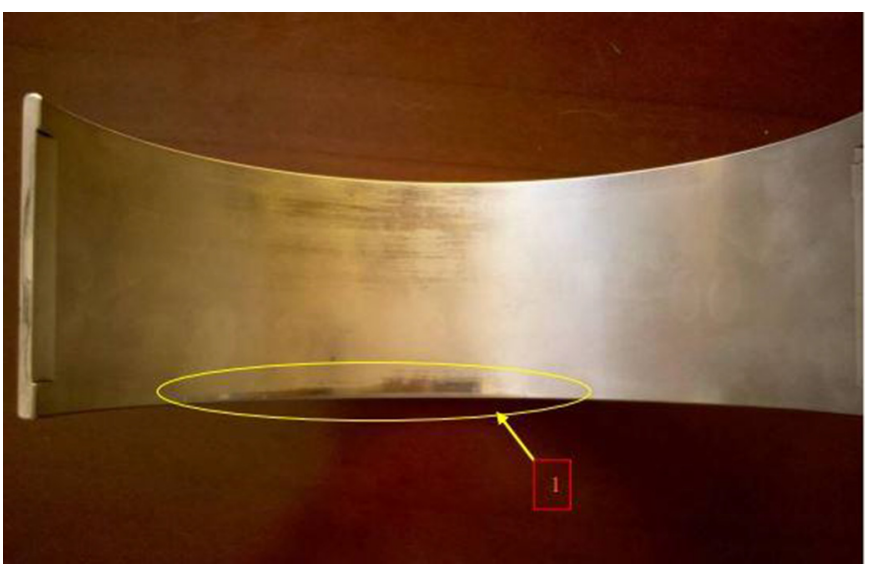

Fig. 1. Edge wear of bearing bushing.

The works mentioned above assumed the journal is aligned, although, as the study carried out by Sun [10] showed, the journal will be misaligned in bearing hole when force acts on the shaft. Therefore, the lubrication performance of the journal bearing may be affected to a different extent. By the experimental analysis, Bouyer and Fillon [11] confirmed that the journal misalignment can yield significant effects on hydrodynamic performance of the plain journal bearing. The study of Sun et al. [12] showed that the journal misalignment and surface roughness have remarkable effects on the elastohydrodynamic performance of crankshaft main bearings. Nikolakopoulos and Papadopoulos [13] developed an analytical model to examine the relationships among friction, misalignment angle, and wear depth of the worn journal bearing under severe lubrication conditions. Nikolakopoulos et al. [14] proposed a multiobjective optimization method for the intact, worn, and misaligned journal bearings, which can support the design of rotating systems. Li et al. [15] applied a new computational fluid dynamics (CFD) method to study the influence of misalignment on the transient flow of a grooved journal bearing, and this method was verified by experimental results. Boedo [16] proposed a hybrid mobility solution method to analyze journal bearings with misalignment under dynamically load, which can improve the computational speed with minimal accuracy loss. Sun et al. [17] carried out a comprehensive study of the plain journal bearing while simultaneously considering the misalignment, surface roughness, elastic deformation, and viscosity-pressure effect. Zhang et al. [18] proposed a method to determine the appropriate design parameters for water-lubricated bearing with journal misalignment. Lv and coworkers [19] investigated the performance of misaligned journal bearing and provided a more efficient method to analyze the load-carrying capacity and equivalent supporting point location. Mallya et al. [20] analyzed the static performance of three-axial water-lubricated journal bearing with misalignment in turbulent regime. The study showed that the friction coefficient of the journal bearing will increase with increase of the Reynolds number under light load, and the increase of misalignment can improve the bearing load capacity. Lv et al. [21] developed a mixed lubrication model with the journal misalignment and wall slip to investigate the performance of the metallic stern bearings. The results showed that in mixed lubrication regime, both journal misalignment and wall slip will increase the friction coefficient of the bearing. Li et al. [22] studied the effect of dissimilar radial clearances on the characteristics of the rotor bearing system with journal misalignment, which revealed that the dissimilarity should be taken into consideration during the design of the rotor bearing system. Han et al. [23] proposed a new parallel elastic hydrodynamic lubrication (EHL) numerical algorithm to study the influence of micro-bottom shapes on the lubrication performance of herringbone-grooved axial piston bearing with journal misalignment. The results showed that the lubrication performance can be remarkably enhanced with the left triangle and rectangle bottom shapes. Jao et al. [24] studied the influence of anisotropic slip on the characteristics of misaligned journal bearings with herringbone grooves, which indicated that the influence of journal misalignment can be diluted by the existence of slip boundary conditions.

Some of the works mentioned above have pointed out that the bushing profiles have great impacts on the lubrication performance of journal bearings; in fact, the performance can be enhanced effectively if the profile is properly selected. Leung et al. [25] presented a steady and dynamic analysis for the spherical journal bearing. The results showed that increasing the length to diameter ratio can increase the load-carrying capacity but reduce the bearing stability. This kind of bearing can also accommodate journal misalignment and resist axial load. El-Gamal [26] presented an analysis for the wedge-shaped journal bearing. The results indicated that this kind of bearing with small wedge angle shows a better performance than cylindrical bearing. Rasheed [27] examined the effects of wedge-shaped, convex, and concave surfaces on the performance of noncylindrical bearing. The results showed a prominent increase in the load-carrying capacity than that of plain cylindrical bearing, and a reduction in friction had also been found. Strzelecki [28] analyzed the lubrication performance of aligned and misaligned hyperboloidal journal bearing. The results showed that the film temperature and pressure distributions along the axial direction can be effected by the hyperboloid profile coefficient. Under the assumed length to diameter ratio and load capacity, the maximum film temperature can present small increase with the increase of the hyperboloidal profile coefficient. Mihailidis et al. [29] presented a precise thermohydrodynamic model that can enable the solution of the film thickness as well as the temperature and pressure distribution. Then, the effects of hourglass-shaped bushing were studied. The results indicated that the parabolic and crowned profiles can significantly increase the minimum film thickness; however, these profiles are difficult to manufacture. Rajput and Sharma [30] investigated the effects of journal's geometric imperfections and misalignment on the performance of four-pocket hybrid 
(a)
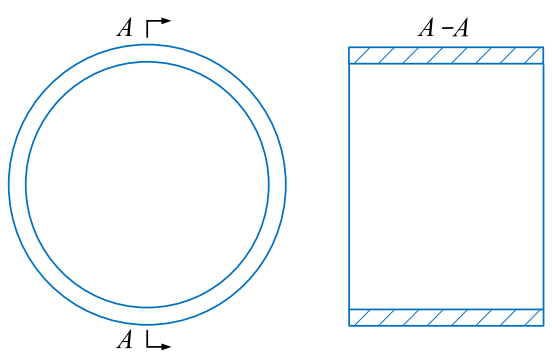

(b)
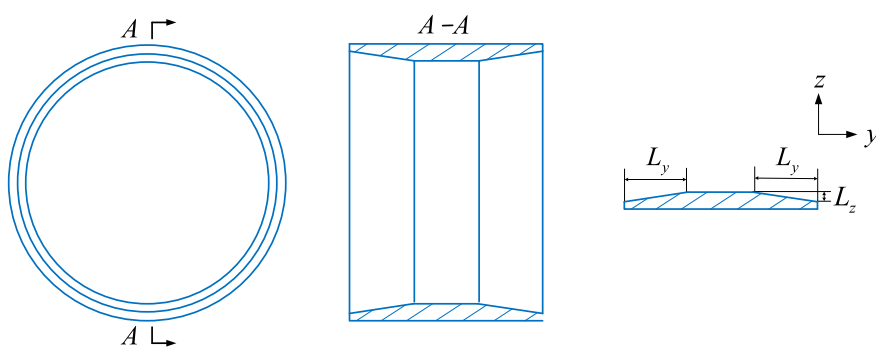

(c)
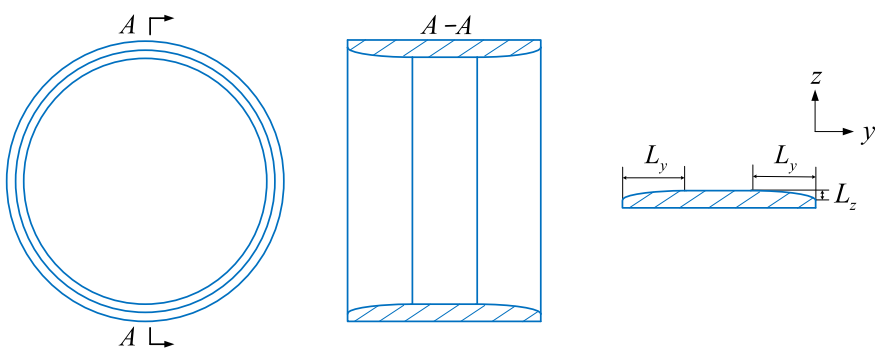

Fig. 2. (a) Plain profile. (b) Double conical profile. (c) Double parabolic profile.

journal bearing. Three kinds of geometric imperfections barrel shape, bell-mouth shape, and undulated shape - are examined. The results showed that the misalignment and geometric imperfections of the journal can deteriorate the performance significantly.

Although some researches have reported on the effects of bushing profiles on the lubrication performance of journal bearing, there are some studies that have simultaneously considered the effects of journal misalignment as well as the elastic deformation and asperity contact when examining the effects of bushing profiles. The innovation of this study is considering the bushing profiles (including the plain profile, double conical profile, and double parabolic profile), journal misalignment, and asperity contact on the elastohydrodynamic lubrication performance of journal bearing simultaneously, while the modification of the bushing profiles due to running-in is neglected. The results reveal that the double parabolic profile with appropriate size can remarkably improve the lubrication performance under steady operating conditions, which may help to reduce the edge wear of journal bearing.
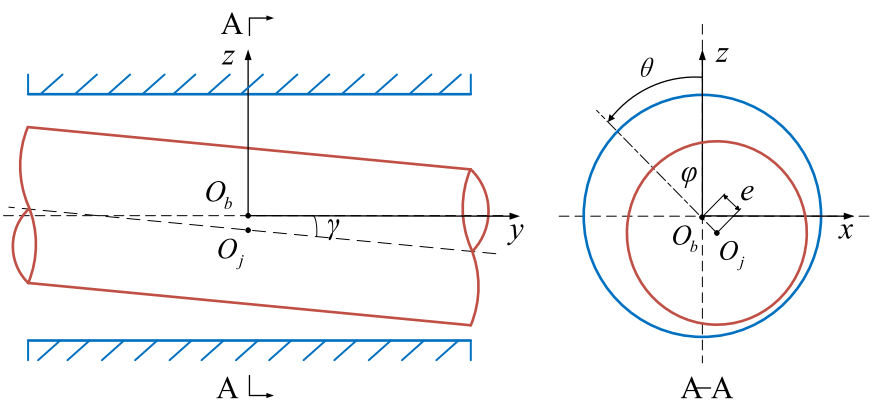

Fig. 3. Misaligned journal bearing.

\section{Theoretical formulation}

\subsection{Geometric model}

Figure 2 shows the three bearing bushing profiles investigated in this article: plain profile, double conical profile, and double parabolic profile.

In Figure 2a, $B$ is the width of plain profile and $d$ is the thickness of the plain profile. In Figures $2 \mathrm{~b}$ and $2 \mathrm{c}$, double conical profile and double parabolic profile distribute symmetrically along the axial direction, which are defined by axial width $L_{y}$ and radial height $L_{z}$, and the parabolic equation in Figure $2 \mathrm{c}$ is $\delta_{z}=\left(L_{z} / L_{y}^{2}\right) y^{2}$. Note that the change of the profiles due to running-in is not considered here.

\subsection{Film thickness}

Figure 3 shows a misaligned journal bearing. For simplicity, only misalignment in the vertical plane is considered.

As the hardness of the journal is much higher than that of bearing bushing, only elastic deformation of bushing surface under film pressure is considered. Thus, the film thickness $h$ is

$$
h=h_{g}+\delta_{e}
$$

where $h_{g}$ is the film thickness without elastic deformation, which is given by

$$
h_{g}=c+e \cos (\theta-\varphi)+y \tan \gamma+\delta_{z}
$$

where $c$ is the radial clearance, $e$ is the eccentricity of the midplane, $\varphi$ is the attitude angle of the midplane, $y$ is the axial coordinate, $\gamma$ is the misalignment angle, $\delta_{z}$ is the clearance caused by double conical profile or double parabolic profile, and $\delta_{e}$ is the elastic deformation of bushing surface.

\subsection{Elastic deformation of bushing surface}

The finite element method based on linear superposition principle is used to calculate the elastic deformation of bushing surface, which can be expressed as [12]

$$
\boldsymbol{\delta}_{\mathbf{e}}=\mathbf{K p}
$$


where $\boldsymbol{\delta}_{\mathrm{e}}$ is the matrix of elastic deformation, $\mathbf{K}$ is the compliance matrix of bushing surface, and $\mathbf{p}$ is the matrix of film pressure.

\subsection{Reynolds equation}

The Reynolds equation based on average flow model is

$$
\begin{aligned}
& \frac{\partial}{\partial x}\left(\phi_{x} \frac{h^{3}}{12 \mu} \cdot \frac{\partial p}{\partial x}\right)+\frac{\partial}{\partial y}\left(\phi_{y} \frac{h^{3}}{12 \mu} \cdot \frac{\partial p}{\partial y}\right) \\
& \quad=\frac{U_{1}+U_{2}}{2} \frac{\partial h_{T}}{\partial x}+\frac{U_{1}-U_{2}}{2} \sigma \frac{\partial \phi_{s}}{\partial x}+\frac{\partial h_{T}}{\partial t}
\end{aligned}
$$

where $\mu$ is oil viscosity, $p$ is the film pressure, $U_{1}$ and $U_{2}$ are velocities of the two surfaces, $\sigma$ is the standard deviation of combined roughness, $\phi_{x}, \phi_{y}$ are the pressure flow factors, $\phi_{s}$ is shear flow factor, and $h_{T}$ is the local film thickness.

For the journal bearing under steady operating conditions, equation (4) can be expressed as follows by the variable transformation $x=R \theta$ :

$$
\begin{gathered}
\frac{1}{R^{2}} \frac{\partial}{\partial \theta}\left(\phi_{x} \frac{h^{3}}{\mu} \cdot \frac{\partial p}{\partial \theta}\right)+\frac{\partial}{\partial y}\left(\phi_{y} \frac{h^{3}}{\mu} \cdot \frac{\partial p}{\partial y}\right) \\
\quad=6 \omega \frac{\partial h_{T}}{\partial \theta}+6 \omega \sigma \frac{\partial \phi_{s}}{\partial \theta}
\end{gathered}
$$

where $\omega$ is angular velocity of journal.

\subsection{Asperity contact pressure}

Based on the asperity contact model proposed by Greenwood and Tripp, the asperity contact pressure $P_{\text {asp }}$ is given by

$$
P_{\text {asp }}=\frac{16 \sqrt{2} \pi}{15}(\eta \beta \sigma)^{2} \sqrt{\frac{\sigma}{\beta}} \cdot E \cdot F_{2.5}(h / \sigma)
$$

where $\eta$ is the number of asperities per unit area, $\beta$ is the mean radius of curvature of the asperities, $\sigma$ is the standard derivation, $E$ is the composite elastic modulus, and $F_{2.5}(h / \sigma)$ is the Gaussian distribution function. Note that in this study, the surface pattern parameter $\gamma$ is assumed as 1 , which means the roughness structure is isotropic.

\subsection{Load equilibrium equation}

The static equilibrium position of the journal center can be obtained by

$$
\mathbf{W}+\mathbf{F}=\mathbf{0}
$$

where $\mathbf{W}$ is the external applied load, $\mathbf{F}$ is the resultant force of hydrodynamic force $\mathbf{F}_{\text {oil }}$, and asperity contact force $\mathbf{F}_{\text {asp }}$, namely, $\mathbf{F}=\mathbf{F}_{\text {oil }}+\mathbf{F}_{\text {asp }}$.

The load equilibrium equations along $x$ - and $z$-axes are

$$
\left\{\begin{array}{l}
W_{x}+F_{x}=0 \\
W_{z}+F_{z}=0
\end{array}\right.
$$

where $W_{x}$ and $W_{z}$ are the bearing loads along $x$ - and $z$-axes, $F_{x}$ and $F_{z}$ are the resultant forces along $x$ - and $z$-axes, which can be expressed as follows:

$$
\left\{\begin{array}{l}
F_{x}=F_{\text {oil } x}+F_{\text {asp } x} \\
F z=F_{\text {oil } z}+F_{\text {asp } z}
\end{array}\right.
$$

where $F_{\text {oil } x}$ and $F_{\text {oil } z}$ are the hydrodynamic forces along the $x$ - and $z$-axes, and $F_{\text {asp } x}$ and $F_{\text {asp } z}$ are the asperity contact forces along the $x$ - and $z$-axes, which can be calculated by

$$
\begin{gathered}
\left\{\begin{array}{l}
F_{\text {oilx }}=+\int_{0}^{B} \int_{0}^{2 \pi} p R \sin \theta d \theta d y \\
F_{\text {oilz }}=-\int_{0}^{B} \int_{0}^{2 \pi} p R \cos \theta d \theta d y
\end{array}\right. \\
\left\{\begin{array}{l}
F_{\text {aspx }}=+\int_{0}^{B} \int_{0}^{2 \pi} p_{\text {asp }} R \sin \theta d \theta d y \\
F_{\text {aspz }}=-\int_{0}^{B} \int_{0}^{2 \pi} p_{\text {asp }} R \cos \theta d \theta d y
\end{array}\right.
\end{gathered}
$$

\subsection{Friction coefficient}

Calculation formula of friction $f$ under mixed lubrication is [21]

$f=\int_{0}^{B} \int_{0}^{2 \pi}\left(\frac{\mu U}{h}\left(\phi_{f}+\phi_{f s}\right)+\phi_{f p} \frac{h}{2 R} \frac{\partial p}{\partial \theta}+\mu_{\text {asp }} \cdot p_{\text {asp }}\right) R d \theta d y$

where $U=\omega R, \phi_{f}, \phi_{f s}, \phi_{f p}$ are shear stress factors and $\mu_{\text {asp }}$ is the boundary friction coefficient.

The friction coefficient $\mu_{f}$ can be obtained by

$$
\mu_{f}=f / F
$$

where $F$ is the amplitude of resultant force, and $F=\sqrt{F_{x}^{2}+F_{z}^{2}}$.

\subsection{Leakage flow rate}

The leakage flow rate $Q_{1}$ from the front end plane of bearings and the leakage flow rate $Q_{2}$ from the rear end plane of bearings are [12]

$$
\left\{\begin{array}{l}
Q_{1}=-\left.\int_{0}^{2 \pi} \phi_{y} \frac{h^{3}}{12 \mu} \frac{\partial p}{\partial y}\right|_{y=0} R d \theta \\
Q_{2}=-\left.\int_{0}^{2 \pi} \phi_{y} \frac{h^{3}}{12 \mu} \frac{\partial p}{\partial y}\right|_{y=B} R d \theta
\end{array}\right.
$$

The total leakage flow rate $Q$ is

$$
Q=\left|Q_{1}\right|+\left|Q_{2}\right|
$$




\section{Numerical procedure and verification}

Apply the finite difference method to discretize equation (5), and then solve the difference equations by overrelaxation iterative method. The Reynolds boundary conditions are adopted and all calculated negative pressures are set equal to zero during the iterative solution. The discretization film pressure can be calculated by

$$
\begin{aligned}
& p_{i, j}^{(k+1)} \\
& =p_{i, j}^{(k)}-\omega_{s}\left[p_{i, j}^{(k)}-\left(\begin{array}{l}
D D_{i, j}-C S_{i, j} \cdot p_{i+1, j}^{(k)}-C N_{i, j} \cdot p_{i-1, j}^{(k+1)} \\
-C E_{i, j} \cdot p_{i, j+1}^{(k)}-C W_{i, j} \cdot p_{i, j-1}^{(k+1)}
\end{array}\right) / C C_{i, j}\right]
\end{aligned}
$$

where $\rho_{i, j}^{(k+1)}$ is the film pressure for node $(i, j)$ at the $(k+1)$ th iteration, $\rho_{i, j}^{(k)}$ is the film pressure for node $(i, j)$ at the $k$ th iteration, and $\omega_{s}$ is the overrelaxation factor, here $\omega_{s}=1.5$. $D D_{i, j}, C S_{i, j}, C N_{i, j}, C E_{i, j}, C W_{i, j}, C C_{i, j}$ are the difference coefficients during the pressure solution.

The pressure convergence condition at the $k$ th iteration is given by

$$
\frac{\sum_{j=1}^{n_{\theta}} \sum_{i=1}^{n_{y}}\left|p_{i, j}{ }^{(k+1)}-p_{i, j}{ }^{(k)}\right|}{\sum_{j=1}^{n_{\theta}} \sum_{i=1}^{n_{y}} p_{i, j}{ }^{(k+1)}} \leq \varepsilon_{p}
$$

where $\varepsilon_{p}$ is the allowable precision for the solution of film pressure, here $\varepsilon_{p}=0.0001 . n_{\theta}$ and $n_{y}$ are the numbers of nodes along the circumferential and axial direction.

Due to a strongly nonlinear coupling between the pressure and elastic deformation, underrelaxation is required in the pressure updating, as shown in equation (18):

$$
p^{(k+1)}=p^{(k)}+\left(p^{(k+1)}-p^{(k)}\right) \times \alpha_{p}
$$

where $\alpha_{p}$ is the underrelaxation factor, here $\alpha_{p}=0.5$. The initial attempt for $\alpha_{p}$ includes $0.01,0.1,0.2,0.5,0.8$, and 1.0. It is found that the computation will fail to converge if $\alpha_{p}>0.5$. The obtained results are same, while the only difference is the computing time. So $\alpha_{p}=0.5$ is used here to ensure a faster convergence of the solution.

When journal bearing is under steady operating conditions, it can be assumed that the resultant force of hydrodynamic force and asperity contact force is approximately equal to the external applied load, more specifically, the position of the journal center can be obtained through correcting attitude angle $\varphi$ and eccentricity ratio $\varepsilon$, where $\varepsilon=e / c$. The correction strategies can be expressed as follows:

$$
\varphi=\varphi+\omega_{\varphi} \arctan \left(\frac{F_{z}}{F_{x}}\right)
$$

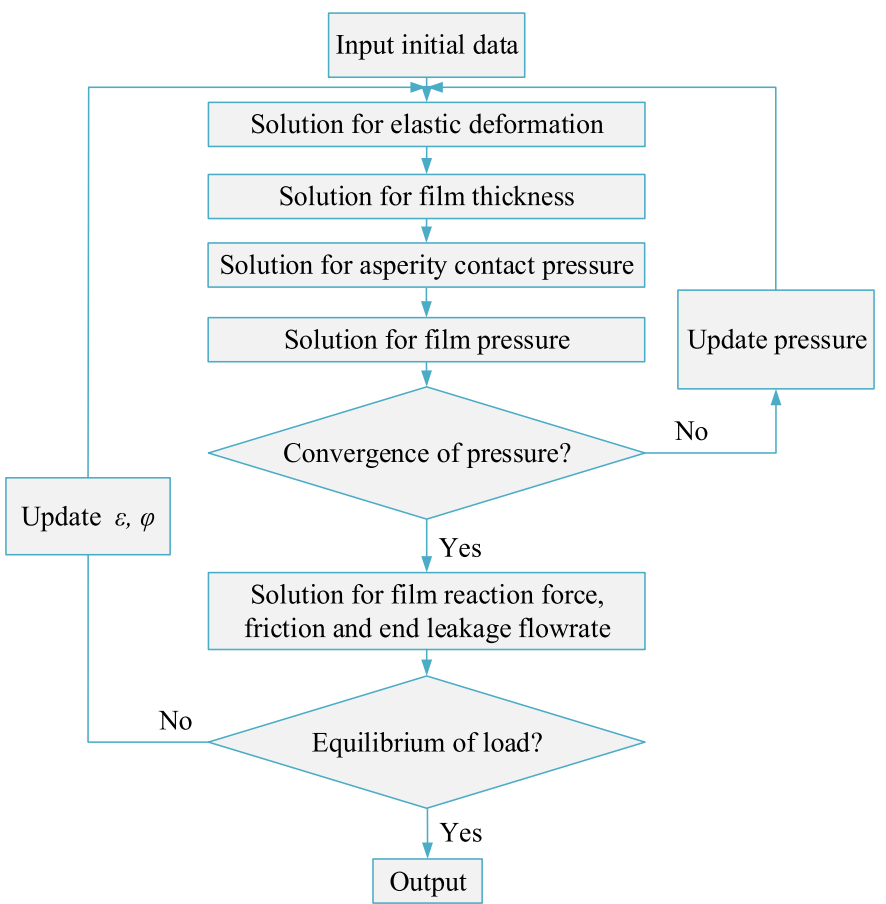

Fig. 4. Flowchart for the computational procedure.

$$
\left\{\begin{array}{l}
\varepsilon=\varepsilon-\omega_{\varepsilon}\left(\frac{F}{W}-1\right)\left(\frac{F}{W} \geq 1\right) \\
\varepsilon=\varepsilon+\omega_{\varepsilon}\left(1-\frac{F}{W}\right)\left(\frac{F}{W}<1\right)
\end{array}\right.
$$

where $W$ is the amplitude of external load, $\omega_{\varphi}$ is the correction factor of $\varphi$, here $\omega_{\varphi}=0.9$, and $\omega_{\varepsilon}$ is the correction factor of $\varepsilon$, here $\omega_{\varepsilon}=0.01$. These two values are also obtained through a multitude of trials.

In this study, the external load is applied along the vertical direction. Accordingly, the equilibrium convergence condition can be given by

$$
\begin{gathered}
\left|\frac{F_{x}}{F_{z}}\right| \leq \operatorname{err}_{\mathrm{xz}} \\
\frac{|F-W|}{W} \leq \operatorname{err}_{W}
\end{gathered}
$$

where $\operatorname{err}_{\mathrm{xz}}$ and $\operatorname{err}_{w}$ are allowable precisions for the calculation of load equilibrium, here $\operatorname{err}_{\mathrm{xz}}=0.001$ and $\operatorname{err}_{w}=0.001$. Note that in real life, bearing misalignment occurs because the bearing supports not only an external load but also an external torque. However, the external torque is not considered here as it is hard to determine its true value. Hence, only the load equilibrium is considered.

The computational procedure is shown in Figure 4.

Verification of this model is conducted by comparing the calculated results of the maximum film pressure with those of Sun's work [10], in which the hydrodynamic lubrication characteristics of a journal bearing with 
Table 1. Bearing parameters used by Sun.

\begin{tabular}{llll}
\hline Parameter & Value & Parameter & Value \\
\hline Journal radius $R(\mathrm{~mm})$ & 30 & Bearing length $B(\mathrm{~mm})$ & 66 \\
Radial clearance $c(\mathrm{~mm})$ & 0.03 & Rotational speed $n(\mathrm{rpm})$ & 3000 \\
Oil viscosity $\mu(\mathrm{mPa} \cdot \mathrm{s})$ & 9 & & \\
\hline
\end{tabular}

Table 2. Comparisons of the maximum film pressure.

\begin{tabular}{|c|c|c|c|c|}
\hline Misalignment angle $\left(^{\circ}\right)$ & 0 & 0.004 & 0.007 & 0.01 \\
\hline Results by Sun (MPa) & 33.06 & 39.60 & 63.58 & 415.35 \\
\hline
\end{tabular}

Table 3. Detailed parameters for the journal bearing.

\begin{tabular}{lll}
\hline Parameter & Value \\
\hline Oil viscosity $\mu(\mathrm{Pa} \cdot \mathrm{s})$ & 0.014 \\
Bearing diameter $D(\mathrm{~mm})$ & 230 \\
Bearing width $B(\mathrm{~mm})$ & 90 \\
Bearing bushing thickness $d(\mathrm{~mm})$ & 5 \\
Radial clearance $c(\mathrm{~mm})$ & 0.14 \\
Standard deviations of the roughness of the bearing surface $\sigma_{b}(\mu \mathrm{m})$ & 0.8 \\
Standard deviations of the roughness of the journal surface $\sigma_{j}(\mu \mathrm{m})$ & 0.4 \\
Elastic modulus of steel backing $E_{s}(\mathrm{GPa})$ & 210 \\
Elastic modulus of copper-lead-tin alloy $E_{a}(\mathrm{GPa})$ & 97 \\
Poisson's ratio of steel backing $v_{s}$ & 0.28 \\
Poisson's ratio of copper-lead-tin alloy $v_{a}$ & 0.3 \\
Specific pressure $(\mathrm{MPa})$ & 32.77 \\
External load $W(\mathrm{kN})$ & 280 \\
\hline
\end{tabular}

misalignment are analyzed. Hence, the elastic deformation of the bushing is ignored in the validation. Bearing parameters used by Sun are listed in Table 1, and the compared results are listed in Table 2 .

As shown in Table 2, the maximum film pressure obtained by this study agree well with those obtained by Sun.

\section{Results and discussions}

Detailed parameters of the journal bearing used in the following numerical analysis are listed in Table 3.

The oil is assumed to be an incompressible Newtonian fluid, which is supplied to the bearing through the axial grooves located at upper half bushing. As the oil supply pressure is far less than the film pressure, the zero pressure can be fixed over the groove, as shown in Figure 5.
The compliance matrix of the bearing house is obtained by the finite element method, which is shown in Figure 6. Grids on the bushing surface are controlled to assure the correspondence between the nodes on the bushing surface and the nodes used to calculate film pressure. The unit type is Solid185, and the constraint is applied to all nodes located at the outer surface of the bearing house.

Mesh refinement analysis is performed based on the plain profile bearing with aligned journal, and the minimum film thicknesses $\left(h_{\min }\right)$ for different meshes are showed in Figure 7 . It can be seen that the solution is converged when the mesh is $80 \times 60$. Considering the solving time and accuracy, $80 \times 60$ mesh is adopted.

In the following numerical analysis, the misalignment angle is chosen as $0.014^{\circ}$. The value is obtained through many trials, which not only ensures the convergence of the computing process but also presents the effect of journal misalignment to the maximum extent. This assumption 


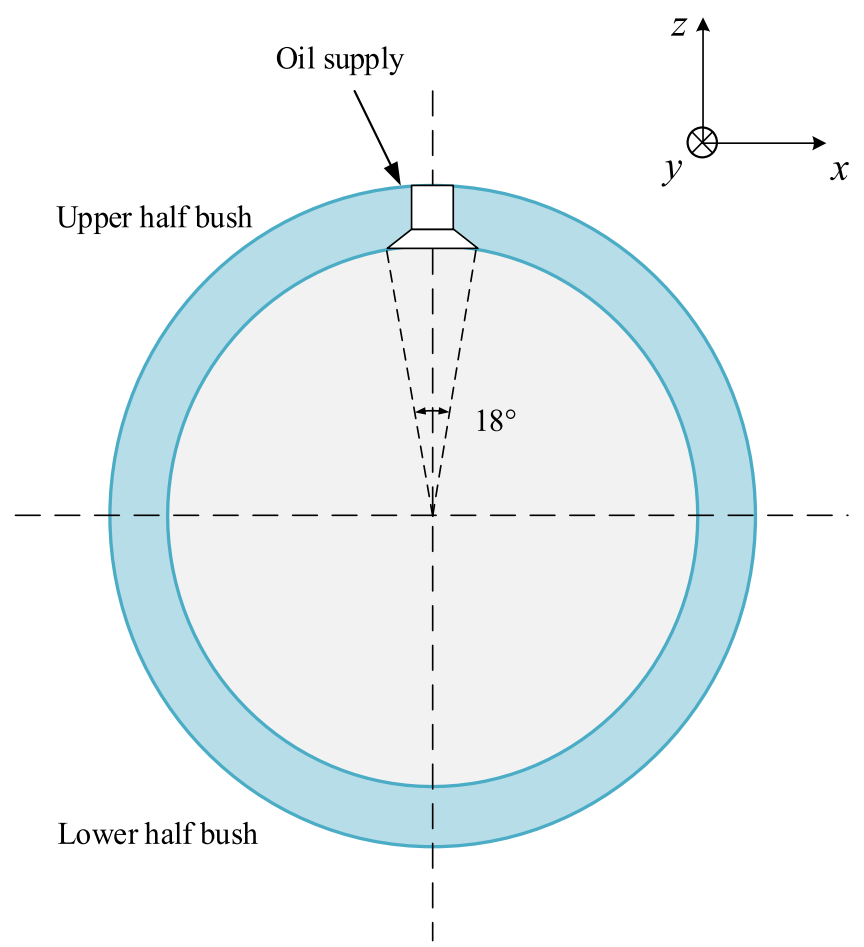

Fig. 5. Schematic diagram of the bearing bushing.

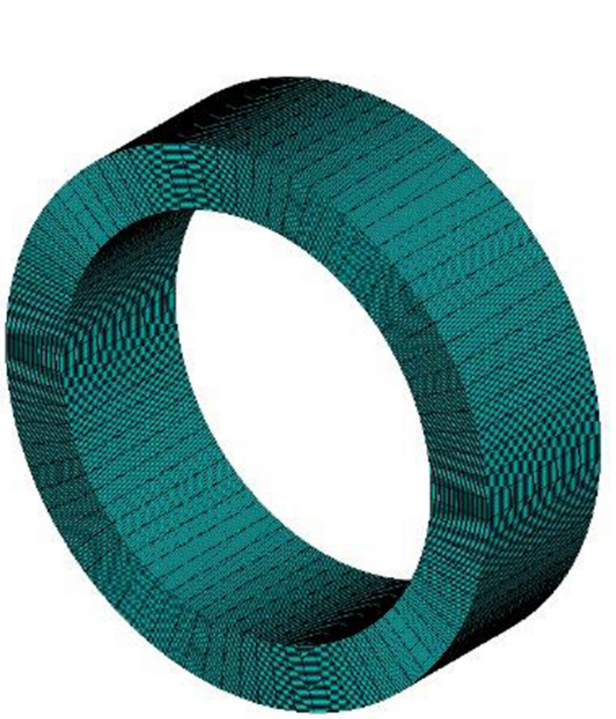

Fig. 6. Finite element model of bearing house.

also keeps the number of variables on a moderate level. The comparisons of the film thickness and pressure distributions of plain profile bearing with aligned and misaligned journal are illustrated in Figure 8. Note that $y$ is the axial coordinate and $\theta$ is the circumferential coordinate. From these figures, it can be seen that the film thickness is unsymmetrical to midplane due to the journal misalignment, and the value of $h_{\min }$ decreases significantly.

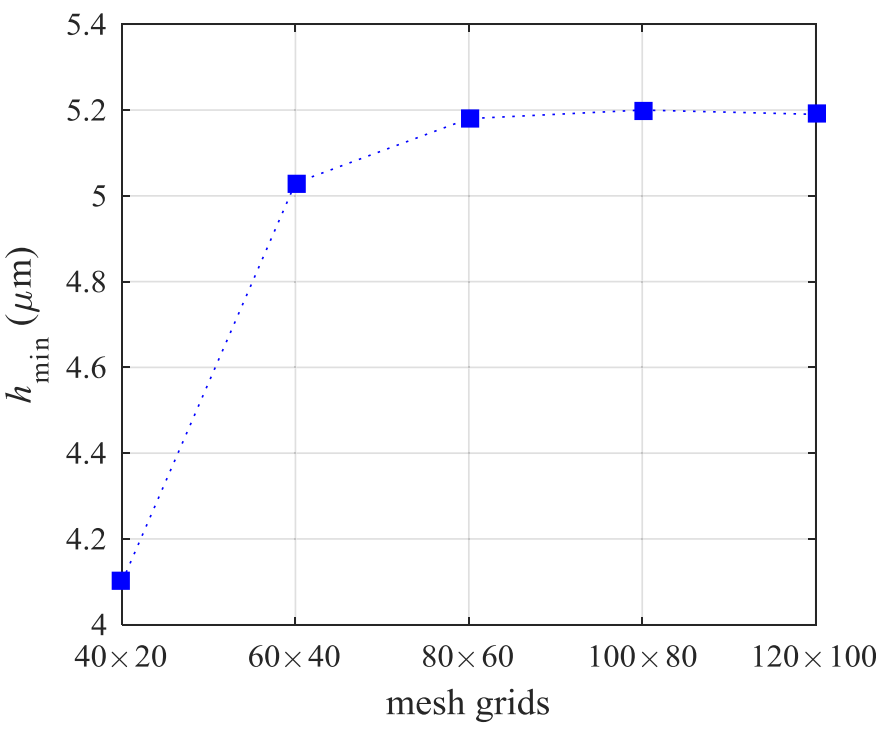

Fig. 7. Mesh refinement analysis.

Consequently, the maximum film pressure $\left(P_{\max }\right)$ moves to the bushing edge and the value of $P_{\max }$ increases remarkably.

Figure 9 shows the elastic deformations corresponding to the aligned and misaligned bearings. As expected, the area where the journal tends to contact the bushing due to journal misalignment has the maximum deformation, and the value of the maximum deformation of the misaligned bearing is greater than that of the aligned bearing. It is also worth noting that, for both the aligned and the misaligned bearings, the elastic deformations are negative in some areas, which means that the directions of local deformations are opposite to the oil film force applied here.

From Figure 8e, it can also be concluded that the aligned bearing is in the hydrodynamic lubrication regime as $h_{\min } / \sigma>3$, where the asperity contact does not appear. For the misaligned bearing, the asperity starts to interact with each other in some areas as $h_{\min } / \sigma<3$. Figure 10 illustrates the asperity contact pressure of the misaligned bearing. It can be seen that the asperity contact concentrates only on one side of the bushing edge, which causes the edge to become progressively worn and finally shows severe edge wear.

Aiming to reduce the edge wear of the bushing, the effects of the plain profile, double conical profile, and double parabolic profile on the performance of the bearing will be discussed. The eccentricity ratio of the midplane $(\varepsilon)$, minimum film thickness $\left(h_{\min }\right)$, maximum asperity contact pressure $\left(P_{\text {asp max }}\right)$, maximum film pressure $\left(P_{\max }\right)$, friction $(f)$, and leakage flow rate $(Q)$ are taken into consideration. For simplicity, the dimensionless parameter $l_{y}=L_{y} / B$ is defined to signify the axial width $L_{y}$, where $l_{y}$ satisfies $0 \leq l_{y} \leq 0.5$, and the interval $\Delta l_{y}=0.05$. Note that $l_{y}=0$ corresponds to the plain profile. The values of radial height $L_{z}$ are 1,2 , and $3 \mu \mathrm{m}$, respectively. Thus, 67 cases will be analyzed.

Figure 11 illustrates the curves of $\varepsilon$ versus $l_{y}$ of the double conical profile and double parabolic profile. 
(a)

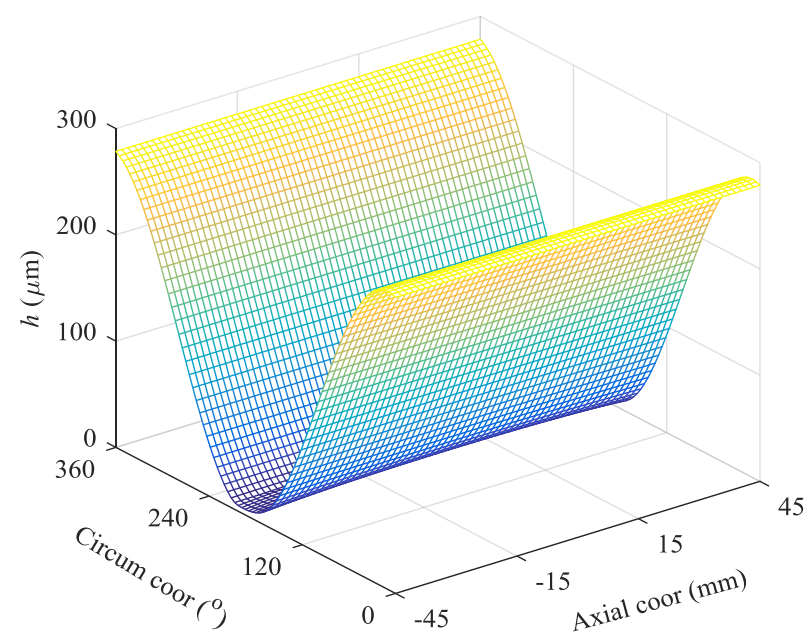

(c)

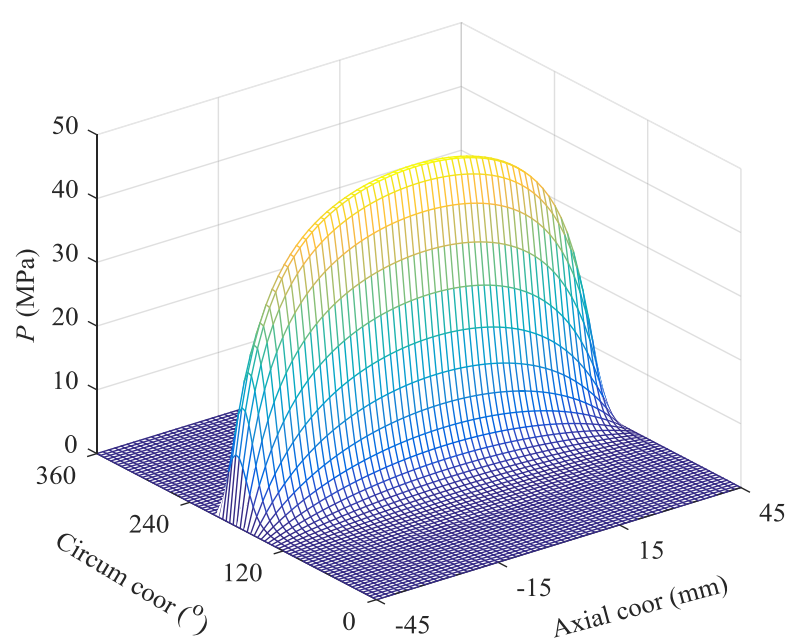

(b)

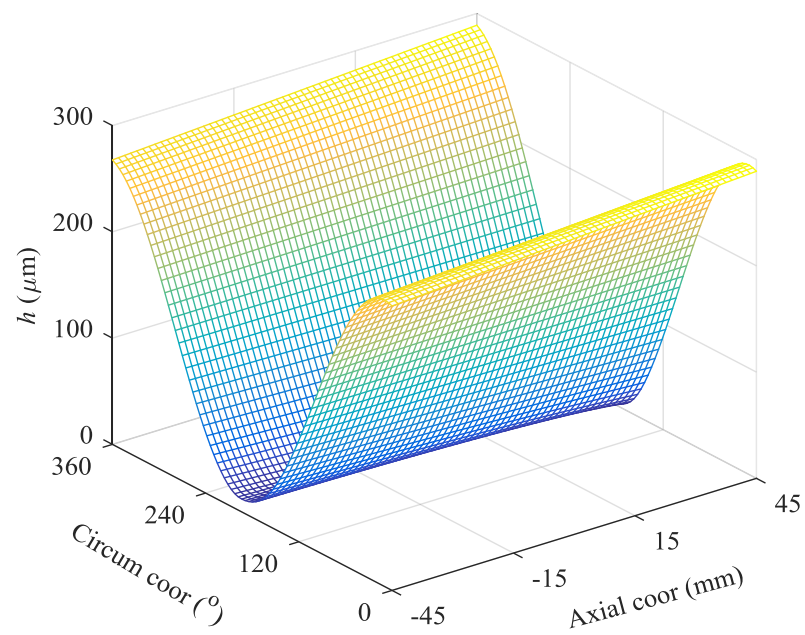

(d)

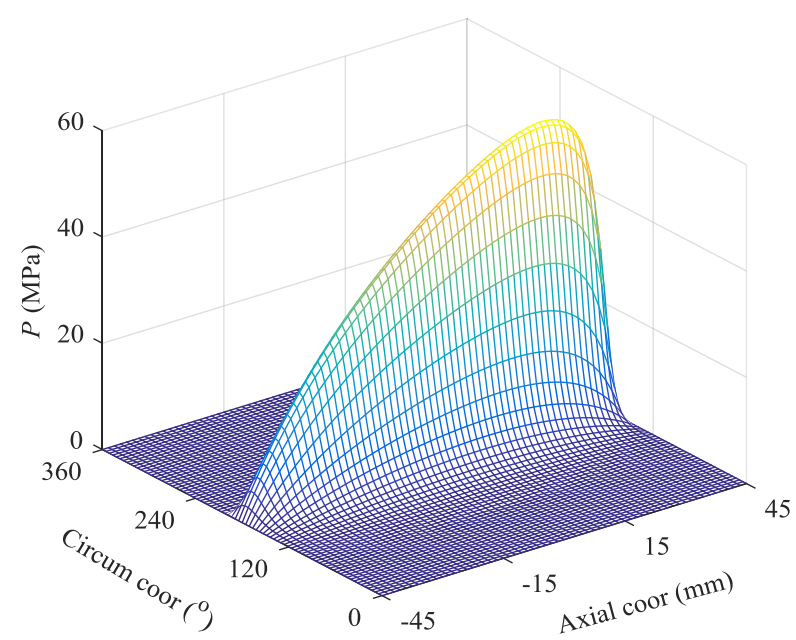

Fig. 8. Comparisons of the film thickness and pressure distributions of plain profile bearing with aligned and misaligned journals $\left(\gamma=0.014^{\circ}\right)$ : (a) film thickness (aligned), film thickness (misaligned), (c) film pressure (aligned), (d) film pressure (misaligned), and (e) the circumferential variations of film thickness and pressure of aligned and misaligned bearing.

It can be seen that for each curve, the $\varepsilon$ shows a clear upward trend with the increasing $l_{y}$. As is well known, a bigger eccentricity ratio means its load-carrying capacity is much weaker and vice versa. Hence, it can be deduced that the longer axial width of the selected profiles has adverse effects on the load-carrying capacity. For the same $l_{y}$, the double parabolic profile with a smaller radial height $L_{z}$ has a smaller $\varepsilon$, which means a larger load-carrying capacity can be generated under this condition. It can be also seen that all values of $\varepsilon$ are greater than 1 due to the significant local elastic deformation.

Figure 12 shows the curves of $h_{\min }$ versus $l_{y}$ of the double conical profile and double parabolic profile. It can be seen that for each curve, the $h_{\min }$ first increases and then decreases with increasing $l_{y}$, and all values of $h_{\min }$ corresponding to the selected profiles are greater than that corresponding to the plain profile. The reason for this trend is that when the axial width is much longer, namely, the profile is more flat, the effects of the profile become increasingly weak. For the same $l_{y}$, the double parabolic profile with a larger radial height $L_{z}$ has a larger $h_{\min }$, which means the lubrication performance can be enhanced more remarkably under this condition.

Figure 13 shows the curves of $P_{\text {asp max }}$ versus $l_{y}$ of the double conical profile and double parabolic profile. It can be seen that, as expected, for each curve, the $P_{\text {asp } \max }$ first decreases and then increases with increasing $l_{y}$, and all values of $P_{\text {aspmax }}$ corresponding to the selected profiles are less than that corresponding to the plain 
(e)
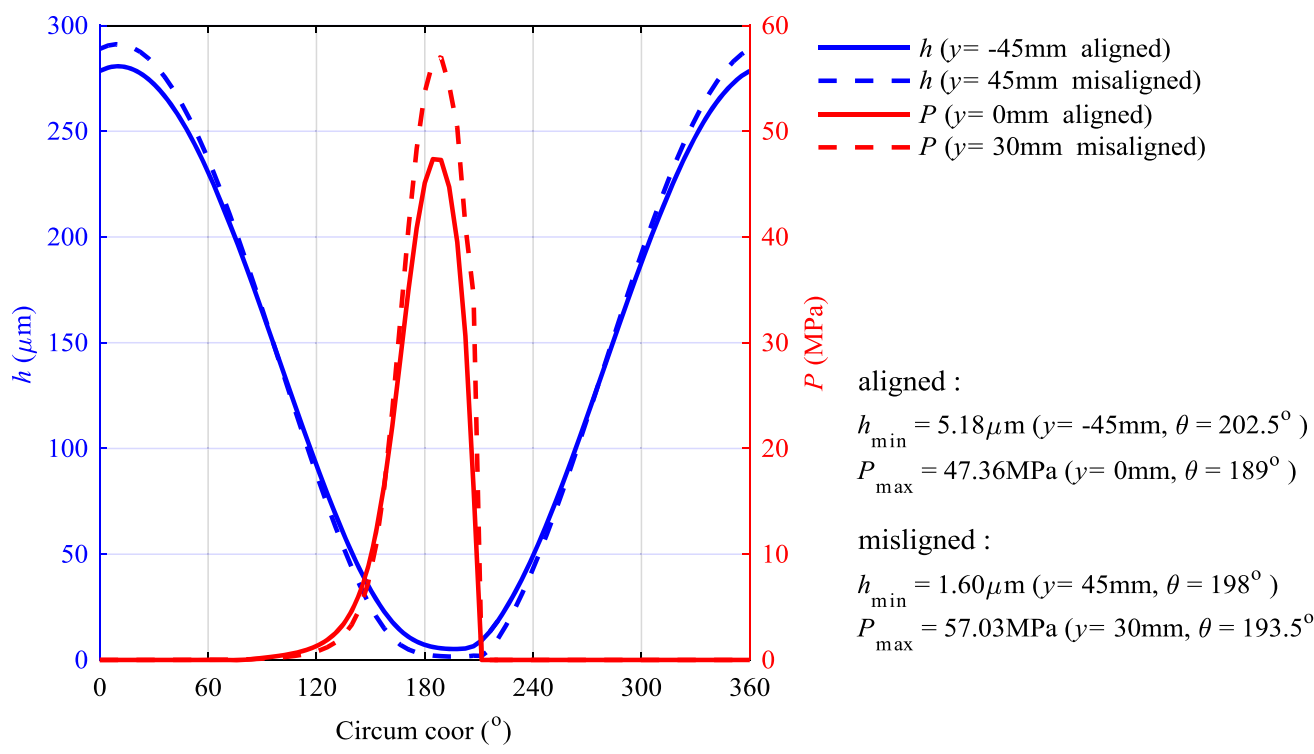

misligned :

$h_{\min }=1.60 \mu \mathrm{m}\left(y=45 \mathrm{~mm}, \theta=198^{\circ}\right)$

$P_{\text {max }}=57.03 \mathrm{MPa}\left(y=30 \mathrm{~mm}, \theta=193.5^{\circ}\right)$

Fig. 8. Continued.

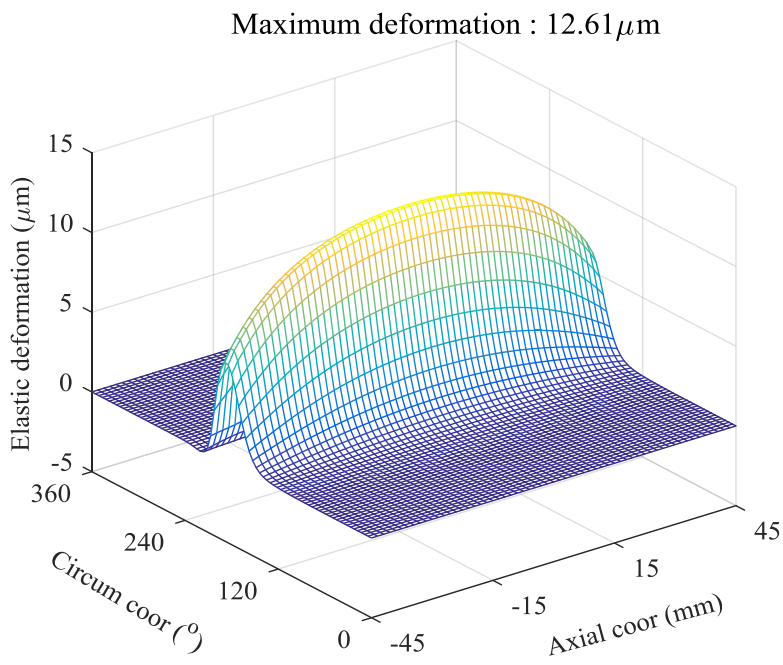

(a)

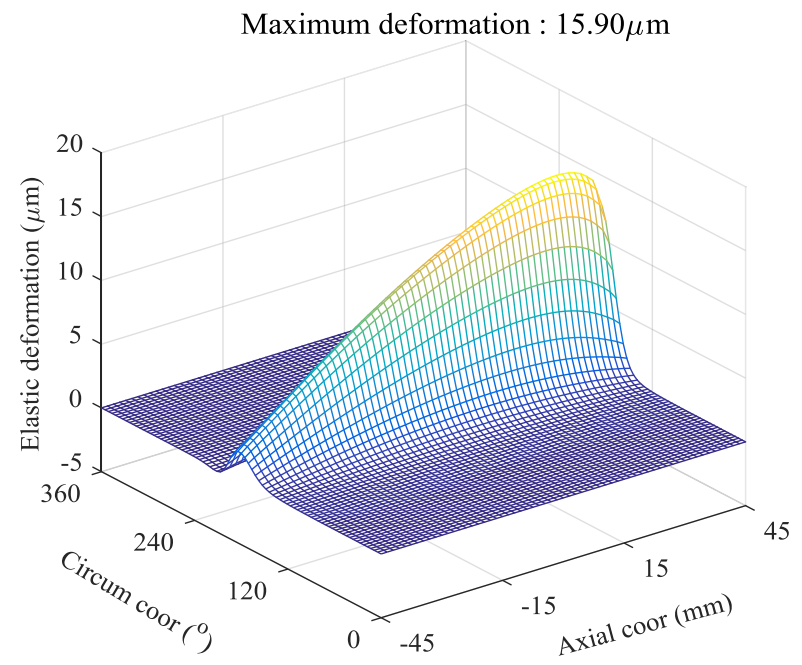

(b)

Fig. 9. Elastic deformations: (a) aligned bearing; (b) misaligned bearing.

profile. As can be seen from Figures 12 and 13, for the same $l_{y}$, the double parabolic profile with a larger radial height $L_{z}$ has a smaller $P_{\text {asp max }}$ as it has a larger $h_{\min }$, and the inflection points of these curves occurs at $l_{y}$ varying from 0.05 to 0.15 depending on the radial height of the selected profiles. It can be deduced that the dimensionless axial width $l_{y}$ varying from 0.05 to 0.15 may give an optimal effect with respect to reducing the edge wear.

Figure 14 shows the curves of $P_{\max }$ versus $l_{y}$ of the double conical profile and double parabolic profile. It can be seen that for each curve, the $P_{\max }$ shows an opposite trend to that of the $P_{\text {asp max }}$. For the same $l_{y}$, the double parabolic profile with a larger radial height $L_{z}$ has a larger $P_{\max }$. The reason for this variation is that the external applied load maintains the same, while the sum of hydrodynamic force and asperity contact force is approximately equal to the external applied load.

Figure 15 shows the curves of $\mu_{f}$ versus $l_{y}$ of the double conical profile and double parabolic profile. It can be seen that for each curve, the $\mu_{f}$ first decreases and then increases with increasing $l_{y}$, except in the case of double parabolic profile with $3 \mu \mathrm{m}$ radial height, which decreases monotonically. All values of $\mu_{f}$ corresponding to the selected profiles 


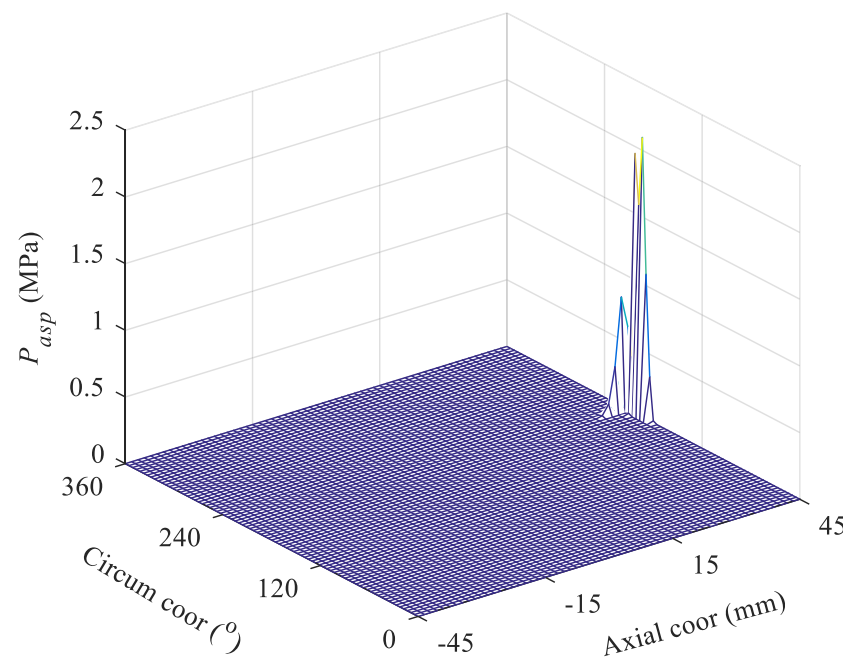

Fig. 10. Asperity contact pressure of misaligned bearing.

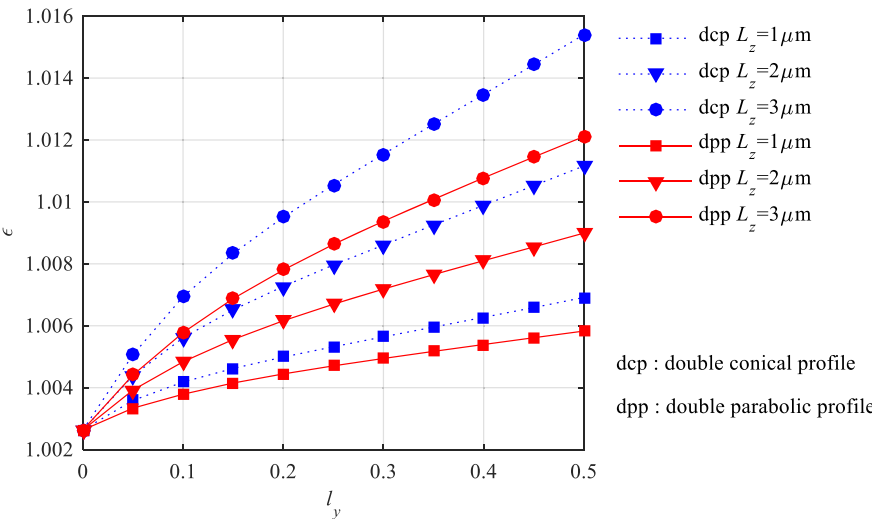

Fig. 11. Eccentricity ratio of the midplane $(\varepsilon)$ versus dimensionless axial width $l_{y}$ of the double conical profile and double parabolic profile.

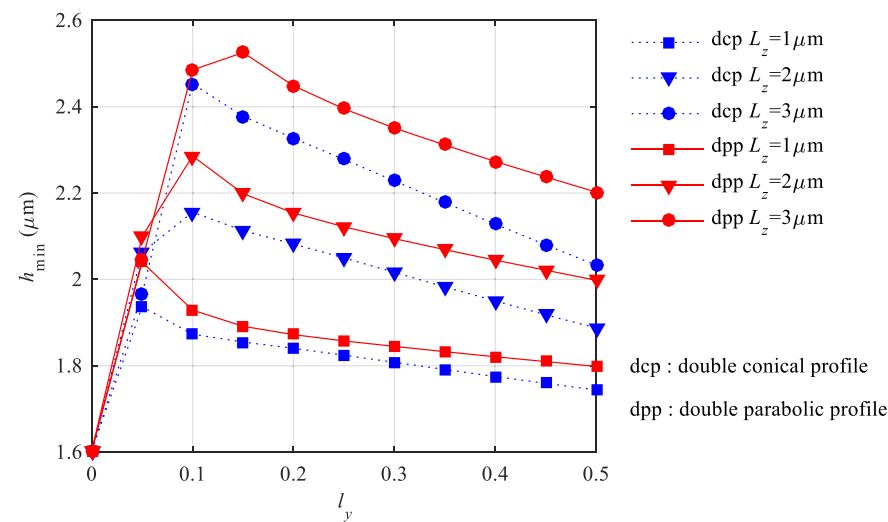

Fig. 12. Minimum film thickness $\left(h_{\min }\right)$ versus dimensionless axial width $l_{y}$ of the double conical profile and double parabolic profile.

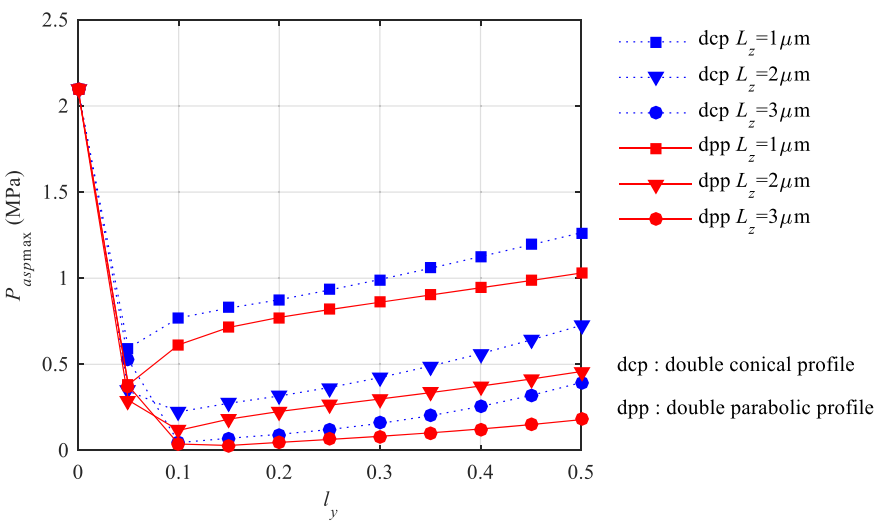

Fig. 13. Maximum asperity contact pressure $\left(P_{\text {asp max }}\right)$ versus dimensionless axial width $l_{y}$ of the double conical profile and double parabolic profile.

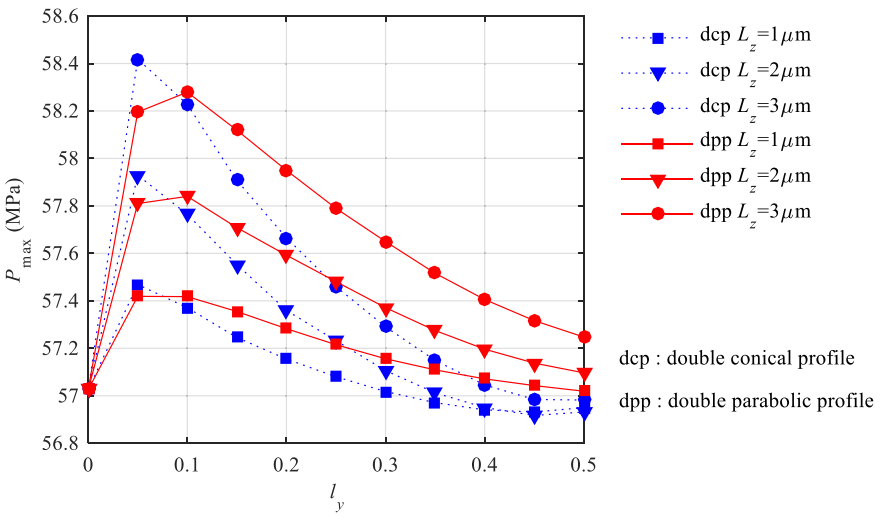

Fig. 14. Maximum film pressure $\left(P_{\max }\right)$ versus dimensionless axial width $l_{y}$ of the double conical profile and double parabolic profile.

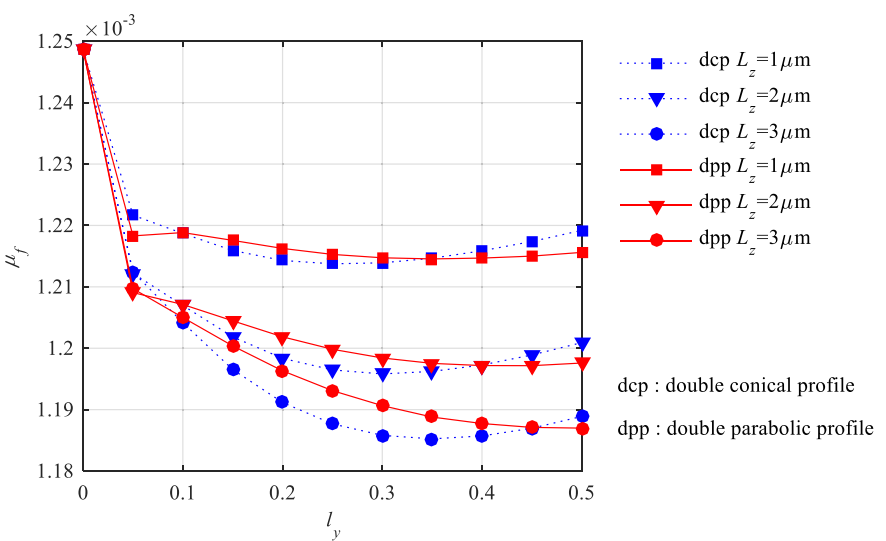

Fig. 15. Friction coefficient $\left(\mu_{f}\right)$ versus dimensionless axial width $l_{y}$ of the double conical profile and double parabolic profile. 


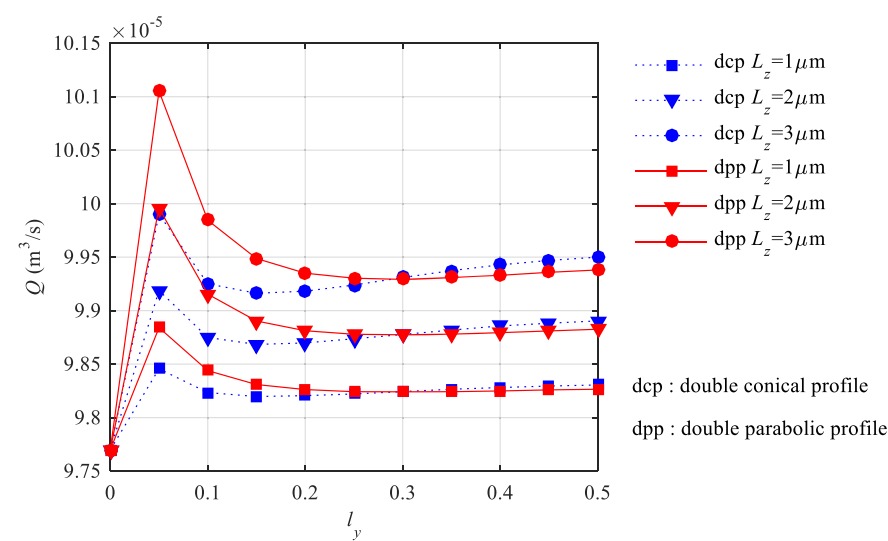

Fig. 16. Leakage flow rate $(Q)$ versus dimensionless axial width $l_{y}$ of the double conical profile and double parabolic profile.

are less than that corresponding to the plain profile, which means the friction power loss can be reduced moderately through changing the bushing profile. The bearing is in the mixed lubrication regime, which assumes that the total friction is the sum of asperity friction and hydrodynamic friction arising from shearing of the oil film. Hence, for the same $l_{y}$ and $L_{z}$, the differences of $\mu_{f}$ between the double conical profile and double parabolic profile can be either positive or negative depending on the specific profile parameters.

Figure 16 shows the curves of $Q$ versus $l_{y}$ of the double conical profile and double parabolic profile. It can be seen that for each curve, the $Q$ first increases and then decreases, and finally slightly increases. This variation trend is somewhat counterintuitive since the leakage flow rate should decrease monotonically when $l_{y} \geq 0.05$. However, as can be seen from Figure 8, the film pressure presents a clear skewed distribution due to the journal misalignment, which increases the pressure gradient at the bushing edge. Hence, the effect of the selected profiles with increasing $l_{y}$ is counterbalanced by the journal misalignment, which leads to a slight increase of the leakage flow rate.

It can be also seen that when $l_{y} \leq 0.25$, for the same $l_{y}$, the double parabolic profile with a larger radial height $L_{z}$ has a larger $Q$, while for $l_{y}>0.25$, the double conical profile with a larger radial height $L_{z}$ has a larger $Q$. All values of $Q$ corresponding to the selected profiles are greater than that corresponding to the plain profile, which means the increase of the leakage flow rate is inevitable.

\section{Conclusions}

A numerical analysis based on EHD theory was carried out to investigate the effects of plain profile, double conical profile, and double parabolic profile on the lubrication performance of journal bearing under steady operating conditions. The following conclusions can be drawn from the numerical results.

First, due to the journal misalignment, the film thickness is unsymmetrical to midplane and the value of the minimum film thickness decreases significantly. Hence,

the maximum film pressure moves to the bushing edge and its value increases remarkably. Meanwhile, the asperity contact only concentrates on one side of the bushing edge, which causes the bushing shows severe edge wear.

Second, compared to the plain profile, both the double conical profile and the double parabolic profile can effectively increase the minimum film thickness, and decrease the asperity contact pressure and friction, which leads to reduced edge wear and friction power loss. However, visible drawbacks of the two profiles are that they reduce the load-carrying capacity to varying degrees, and slightly increase the leakage flow rate.

Third, both the two profiles can improve the lubrication performance to varying degrees depending on the specific profile parameters. For this specific journal bearing, the double parabolic profile with radial height $L_{z}=2 \mu \mathrm{m}$ and dimensionless axial width $l_{y}=0.1$ has a superior performance than others, which offers a good compromise regarding the aforementioned performance parameters.

This study makes a primary exploration about the effects of bushing profiles on the elastohydrodynamic lubrication. In future work, the thermal effects will be considered, and the dynamic characteristics of the double conical profile and double parabolic profile will be investigated.

\section{Nomenclature}

$D$

$B$

$d$

$L_{y}$

$L_{z}$

$\delta_{z}$

$h$

$h_{0}$

\section{$c$}

$e$

$\varphi$

$\gamma$

$\delta_{e}$

\section{$\boldsymbol{\delta}_{\mathrm{e}}$}

K

p

$\mu$

$p$

$U_{1}, U_{2}$

$\sigma$

$\phi_{x}, \phi_{y}$

$\phi_{s}$

$h_{T}$

$\omega$

W

$\mathbf{F}$
Bearing diameter

Width of plain profile

Thickness of plain profile

Axial width of double conical/parabolic profile

Radial height of double conical/parabolic profile

Clearance caused by double conical parabolic profile

Film thickness

Film thickness without elastic deformation of bushing surface

Radial clearance

Eccentricity

Eccentricity angle

Misalignment angle

Elastic deformation of bearing bushing surface

Matrix of elastic deformation

Compliance matrix of bearing bushing surface

Matrix of film pressure

Oil viscosity

Film pressure

Velocities of the two surfaces

Standard deviation of combined roughness

Pressure flow factors

Shear flow factor

Local film thickness

Angular velocity of journal

External applied load

Resultant force of hydrodynamic force and asperity contact force 


\begin{tabular}{|c|c|}
\hline $\mathbf{F}_{\text {oil }}$ & Hydrodynamic force \\
\hline $\mathbf{F}_{\text {asp }}$ & Asperity contact force \\
\hline$W_{x}, W_{z}$ & External applied loads along the $x$ - and $z$-axes \\
\hline$F_{x}, F_{z}$ & Resultant force along the $x$ - and $z$-axes \\
\hline$F_{\text {oil } x}, F_{\text {oil } z}$ & $\begin{array}{l}\text { Hydrodynamic forces along the } x \text { - and } \\
z \text {-axes }\end{array}$ \\
\hline$F_{\text {asp } x}, F_{\text {asp } z}$ & $\begin{array}{l}\text { Asperity contact forces along the } x \text { - and } \\
z \text {-axes }\end{array}$ \\
\hline$W$ & Amplitude of the external applied load \\
\hline$F$ & Amplitude of the resultant force \\
\hline$P_{\text {asp }}$ & Asperity contact pressure \\
\hline$\eta$ & Number of asperities per unit area \\
\hline$\beta$ & Mean radius of curvature of the asperities \\
\hline$E$ & Composite elastic modulus \\
\hline$F_{2.5}(h / \sigma)$ & Gaussian distribution function \\
\hline$\phi_{f}, \phi_{f s}, \phi_{f p}$ & Shear stress factors \\
\hline$\mu_{\text {asp }}$ & Friction coefficient \\
\hline$Q_{1}$ & Leakage flow rate from the front end plane \\
\hline$Q_{2}$ & Leakage flow rate from the rear end plane \\
\hline$Q$ & Total leakage flow rate \\
\hline$\omega_{s}$ & Overrelaxation factor \\
\hline$\alpha_{p}$ & Underrelaxation factor \\
\hline$\varepsilon_{p}$ & $\begin{array}{l}\text { Allowable precision for the calculation of film } \\
\text { pressure }\end{array}$ \\
\hline$\varepsilon$ & Eccentricity ratio \\
\hline$\omega_{\varphi}$ & Correction factor of $\varphi$ \\
\hline & Correction factor of $\varepsilon$ \\
\hline $\operatorname{err}_{x z}, \operatorname{err}_{W}$ & $\begin{array}{l}\text { Allowable precision for the calculation of load } \\
\text { equilibrium }\end{array}$ \\
\hline$\sigma_{b}$ & $\begin{array}{l}\text { Standard deviations of the roughness of the } \\
\text { bearing surface }\end{array}$ \\
\hline$\sigma_{j}$ & $\begin{array}{l}\text { Standard deviations of the roughness of the } \\
\text { journal surface }\end{array}$ \\
\hline$E_{s}$ & Elastic modulus of steel backing \\
\hline$E_{a}$ & Elastic modulus of copper-lead-tin alloy \\
\hline$v_{s}$ & Poisson's ratio of steel backing \\
\hline$v_{a}$ & Poisson's ratio of copper-lead-tin alloy \\
\hline$n_{\theta}, n_{y}$ & $\begin{array}{l}\text { Numbers of nodes along the circumferential } \\
\text { and axial direction }\end{array}$ \\
\hline$h_{\min }$ & Minimum film thickness \\
\hline$P_{\max }$ & Maximum film pressure \\
\hline & Maximum asperity contact pressure \\
\hline & Friction coefficient \\
\hline$l_{y}$ & $\begin{array}{l}\text { Dimensionless axial width of double conical/ } \\
\text { parabolic profile }\end{array}$ \\
\hline
\end{tabular}

Acknowledgement. This work is supported by the National Natural Science Foundation of China (51809057) and Marine Low Speed Engine Project - Phase I (Grant No. CDGC01-KT11).

\section{References}

[1] N. Patir, H.S. Cheng, An average flow model for determining effects of three-dimensional roughness on partial hydrodynamic lubrication, J. Lubr. Technol. 100 (1978) 12-17

[2] N. Patir, M.S. Cheng, Application of average flow model to lubrication between rough sliding surfaces, J. Lubr. Technol. 101 (1979) 220-229
[3] J.A. Greenwood, J.H. Tripp, The contact of two nominally flat rough surfaces, Proc. Inst. Mech. Eng. 185 (1970) $625-633$

[4] K.F. Dufrane, J.W. Kannel, T.H. McCloskey, Wear of steam turbine journal bearings at low operating speeds, J. Lubr. Technol. 105 (1983) 313-317

[5] M. Fillon, J. Bouyer, Thermohydrodynamic analysis of a worn plain journal bearing, Tribol. Int. 37 (2004) $129-136$

[6] J. Bouyer, M. Fillon, I. Pierre-Danos, Influence of wear on the behavior of a two-lobe hydrodynamic journal bearing subjected to numerous startups and stops, J. Tribol. 129 (2007) 205-208

[7] S.M. Chun, M.M. Khonsari, Wear simulation for the journal bearings operating under aligned shaft and steady load during start-up and coast-down conditions, Tribol. Int. 97 (2016) 440-466

[8] Y. Wang, Z. Yin, G. Gao, X. Zhang, Analysis of the performance of worn hydrodynamic water-lubricated plain journal bearings considering cavitation and elastic deformation, Mechanics \& Industry 18 (2017) 1-12

[9] G.K. Kalavathi, P.A. Dinesh, K. Gururajan, Influence of roughness on porous finite journal bearing with heterogeneous slip/no-slip surface, Tribol. Int. 102 (2016) 174-181

[10] J. Sun, G. Changlin, Hydrodynamic lubrication analysis of journal bearing considering misalignment caused by shaft deformation, Tribol. Int. 37 (2004) 841-848

[11] J. Bouyer, M. Fillon, An experimental analysis of misalignment effects on hydrodynamic plain journal bearing performances, J. Tribol. 124 (2002) 313-319

[12] J. Sun, C.L. Gui, Z.H. Wang, Research on elastohydrodynamic lubrication of a crankshaft bearing with a rough surface considering crankshaft deformation, Proc. Inst. Mech. Eng. D: J. Automobile Eng. 222 (2008) 2403-2414

[13] P.G. Nikolakopoulos, C.A. Papadopoulos, A study of friction in worn misaligned journal bearings under severe hydrodynamic lubrication, Tribol. Int. 41 (2008) 461-472

[14] P.G. Nikolakopoulos, C.I. Papadopoulos, L. Kaiktsis, Elastohydrodynamic analysis and Pareto optimization of intact, worn and misaligned journal bearings, Meccanica 46 (2011) 577-588

[15] Q. Li, S.-1. Liu, X.-H. Pan, S.-Y. Zheng, A new method for studying the $3 \mathrm{D}$ transient flow of misaligned journal bearings in flexible rotor-bearing systems, J. Zhejiang Univ. Sci. A 13 (2012) 293-310

[16] S. Boedo, A hybrid mobility solution approach for dynamically loaded misaligned journal bearings, J. Tribol. 135 (2013) $1-5$

[17] J. Sun, X. Zhu, L. Zhang, X. Wang, C. Wang, H. Wang, X. Zhao, Effect of surface roughness, viscosity-pressure relationship and elastic deformation on lubrication performance of misaligned journal bearings, Ind. Lubr. Tribol. 66 (2014) 337-345

[18] X. Zhang, Z. Yin, D. Jiang, G. Gao, Y. Wang, X. Wang, Load carrying capacity of misaligned hydrodynamic waterlubricated plain journal bearings with rigid bush materials, Tribol. Int. 99 (2016) 1-13

[19] F. Lv, N. Ta, Z. Rao, Analysis of equivalent supporting point location and carrying capacity of misaligned journal bearing, Tribol. Int. 116 (2017) 26-38

[20] R. Mallya, S.B. Shenoy, R. Pai1, Static characteristics of misaligned multiple axial groove water-lubricated bearing in the turbulent regime, Proc. Inst. Mech. Eng. J: J. Eng. Tribol. 231 (2017) 385-398 
[21] F. Lv, Z. Rao, N. Ta, C. Jiao, Mixed-lubrication analysis of thin polymer film overplayed metallic marine stern bearing considering wall slip and journal misalignment, Tribol. Int. 109 (2017) 390-397

[22] J. Li, H. Cao, L. Lv, H. Yang1, L. Zhang, Influence of dissimilar radial clearances on the performance of hydrodynamic rotorbearing systems considering misalignment effects, Proc. Inst. Mech. Eng. J: J. Eng. Tribol. 232 (2018) 231-243

[23] Y. Han, J. Wang, G. Zhou, K. Xiao, J. Li, Micro-bottom shape effects on the misaligned herringbone grooved axial piston bearing with a new parallel algorithm, Proc. Inst. Mech. Eng. J: J. Eng. Tribol. 231 (2017) 637-654

[24] H. Jao, W. Li, T. Liu, Analysis of misaligned journal bearing with herringbone grooves: consideration of anisotropic slips, Microsyst. Technol. 23 (2017) 4687-4698

[25] P.S. Leung, I.A. Craighead, T.S. Wilkinson, An analysis of the steady state and dynamic characteristics of a spherical hydrodynamic journal bearing, J. Tribol. 111 (1989) 459-467
[26] H.A. El-Gamal, Analysis of the steady state performance of a wedge-shaped hydrodynamic journal bearing, Wear 184 (1995) 111-117

[27] H.E. Rasheed, The elastohydrodynamic lubrication of heavily loaded journal bearing having non-cylindrical axial geometry, Tribol. Series 32 (1997) 675-683

[28] S. Strzelecki, Operating characteristics of heavy loaded cylindrical journal bearing with variable axial profile, Mater. Res. 8 (2005) 481-486

[29] A. Mihailidis, V. Bakolas, K. Panagiotidis, K. Poulios, C. Sachanas, Influence of the bushing geometry on the thermohydrodynamic performance of a misaligned journal bearing, Proc. Inst. Mech. Eng. J: J. Eng. Tribol. 224 (2010) $37-53$

[30] A.K. Rajput, S.C. Sharma, Combined influence of geometric imperfections and misalignment of journal on the performance of four pocket hybrid journal bearing, Tribol. Int. 97 (2016) 59-70

Cite this article as: C. Liu, B. Zhao, W. Li, X. Lu, Effects of bushing profiles on the elastohydrodynamic lubrication performance of the journal bearing under steady operating conditions, Mechanics \& Industry 20, 207 (2019) 